\title{
Testing of Different Skeletal and Global Mechanisms for Modeling Combustion of Degradation Gases Involved in Wildland Fire
}

\author{
VIRGINIE TIHAY, ALBERT SIMEONI and PAUL-ANTOINE SANTONI \\ SPE- UMR 6134 CNRS, University of Corsica, Campus Grossetti, BP 52, 20250 Corte, France
}

\begin{abstract}
To simulate forest fires, there is a need of simple models for gas oxidation. The aim of this work is to provide such a model. Using numerical methods, the transient equations for the conservation of mass, momentum, energy and chemical species were solved as well as the radiative transfer equation for a laminar flame. Skeletal and global mechanisms of combustion including the main degradation gases released by forest fuels $\left(\mathrm{CO}_{2}, \mathrm{CO}, \mathrm{CH}_{4}\right.$ and $\left.\mathrm{H}_{2} \mathrm{O}\right)$ were tested. Their evaluation was carried out following two criteria: their computational time and their accuracy. The skeletal mechanisms provide results close to the experiments. However, they require too long computational times whatever the number of reactions. Then, two global mechanisms considering different gases were investigated as they necessitate less computational time. The comparison between the simulated and predicted temperatures points out that the mechanism containing only carbon monoxide as fuel underestimates significantly the temperature in the fire plume. On the contrary, the results obtained with global mechanisms including both methane and carbon monoxide are in good agreement with the experiments. These conclusions lead to the proposal of a simple and reliable combustion model for forest fire simulations, which considers only two reactions steps including methane.
\end{abstract}

KEYWORDS: wildfires, combustion modeling, skeletal mechanism, global reactions, degradation gases.

\section{NOMENCLATURE LISTING}

$\begin{array}{llll}a & \text { absorptivity } & v & \text { axial coordinate of gas velocity } \\ D & \text { mass diffusivity } & \vec{V} & \text { gas velocity } \\ e & \text { total energy } & Y & \text { mass fraction of species } \\ g & \text { gravity } & Z & \text { axial coordinate } \\ h & \text { enthalpy } & \text { Greek } & \\ I & \text { radiant intensity } & \lambda & \text { thermal conductivity } \\ N & \text { number of species } & \mu & \text { viscosity } \\ \dot{Q} & \text { volumetric heat source } & \rho & \text { density } \\ r & \text { radial coordinate } & \overline{\bar{\tau}} & \text { viscous stress tensor } \\ \vec{r} & \text { direction vector } & \sigma & \text { Stefan-Boltzmann constant } \\ \vec{R} & \text { radiant heat flux } & \dot{\omega} & \text { mass rate of production } \\ s & \text { norm of the unit vector along the } & & \\ & \text { radiant intensity path } & \text { Subscripts } \\ \vec{S} & \text { unit vector along the radiant } & & \\ & \text { intensity path } & & \text { species } i \\ t & \text { time } & j & \text { species } j \\ T & \text { temperature } & g & \text { gas phase } \\ u & \text { radial coordinate of gas velocity } & & \end{array}$

\section{INTRODUCTION}

The understanding of the physical mechanisms that control the ignition and the spread of wildfires constitutes a major objective for the management and the preservation of forest areas. Three types of modeling approaches have emerged. The first one includes statistical models [1]. The second one incorporates empirical models [2]. Based on a detailed description of the heat transfer mechanisms, which 
govern the fire propagation, the physical models [3-5] are the third set of models. Recently, the new generation of physical models tends to include more and more physical mechanisms [6-8]. However, the numerous sub-models, which describe the physics of the fire, need to be improved. In this study, we focus on the gas phase combustion of degradation gases as this domain is poorly modeled by the existing physical models of wildland fire. The combustible part of the devolatilization products is indeed generally considered to be carbon monoxide burning in air [5], whatever vegetation species. The production/destruction rates are often evaluated with the Eddy Dissipation Concept [8] which does not considered in detail the combustion mechanism of the gas species. The forest fire models need also a simple reliable model for the oxidation of the degradation gases. Although a detailed reaction mechanism (over a hundred reactions and around 50 species) is possible for an accurate description of the chemistry, it is currently impractical for predicting the behavior of wildfires as the computational time is too long. Therefore, the idea of using skeletal and global mechanisms is attractive.

The aim of this work is to test different combustion mechanisms for modeling the oxidation of degradation gases released by vegetative fuels. To focus on the combustion kinetics in gas phase, the modeling was concentrated on laminar flames obtained from the burning of crushed forest fuels [9]. A primitive variable formulation was employed to solve the transient conservation equations of mass, momentum, energy, species as well as radiation. The first step of the study begins with the determination of a modeled composition of degradation gases. Different gas mixtures were investigated thanks to the skeletal mechanism developed by Leroy et al. [10] including carbon monoxide, methane and $\mathrm{C}_{2}$ hydrocarbons. Since this mechanism is time consuming, various skeletal mechanisms which are made up of fewer reactions were studied and compared to the mechanism of Leroy et al. in order to decrease the computational time without losing accuracy. Then, two global mechanisms were tested and compared to skeletal ones to establish a reliable model containing as fewer reactions as possible. Finally, the predictions obtained with this model were compared to experiments. The paper is organized as follows. In the first section, a reminder of the experimental procedures is provided. In the second section, the numerical method is exposed. Then, the study of the different combustion mechanisms is presented. Finally, the numerical results are compared to the experimental data.

\section{EXPERIMENTAL DEVICE}

Experiments were carried out to obtain laminar flames and collect data (gas composition, mass flow rate, flame radius, temperature distribution) for the implementation and the test of different combustion models. A more detailed description of the experimental devices and of the experimental data is given in Tihay et al. [9].

\section{Forest fuels}

We studied the burning of three Mediterranean fuels involved in wildfires: two pines (Pinus laricio and Pinus halepensis) and a heather Erica arborea. They were collected in winter during a period of hydrous stress for vegetation. Before experiments, the plants were oven-dried at $60^{\circ} \mathrm{C}$ during 24 hours. Then, they were crushed and sieved to a particle size of $0.6-0.8 \mathrm{~mm}$. This processing allows producing laminar flames. It permits to study more accurately the effects of combustion kinetics on the flame which are often hidden by the turbulence.

\section{Analysis of degradation gases}

The composition of the degradation gases was determined thanks to a tube furnace apparatus used as pyrolyser. Thermogravimetric analysis showed that the most important degradation of the sample occurs between 250 and $425^{\circ} \mathrm{C}$ [11]. We chose to study the degradation gases released during this range of temperature. The pyrolysis was made under inert atmosphere by using nitrogen flow. The combustion chamber was filled with $4 \mathrm{~g}$ of crushed sample. Gases were collected into a gas sampler. Then, the gas sampler was directly attached either to gas chromatographs (Flame Ionization Detector and Thermal Conductivity Detector) or to a hygrometer (EdgeTech Model 2001 Series DewPrime) measuring the dew point with a resolution of $0.1^{\circ} \mathrm{C}$. At least three repetitions were carried out. Degradation gases mainly consist of $\mathrm{CO}_{2}, \mathrm{CO}, \mathrm{CH}_{4}, \mathrm{H}_{2} \mathrm{O}$, and lower amounts of $\mathrm{H}_{2}, \mathrm{C}_{2}, \mathrm{C}_{3}$ and $\mathrm{C}_{4}$ hydrocarbons (Table 1). 


\section{Burning experiments}

The fuel sample was in the shape of a cylinder with a diameter of $3.5 \mathrm{~cm}$, a depth of $5 \mathrm{~mm}$ and a mass of $1.5 \mathrm{~g}$. It was positioned on a load cell in order to measure the fuel mass loss as a function of time (Fig. 1). To insure a fast and homogeneous ignition, a small amount of ethanol $(0.7 \mathrm{~mL})$ was spread uniformly on the fuel sample and was ignited with a flame torch. An array of 11 thermocouples was positioned above the fuel sample along the flame axis. The first thermocouple was placed $1 \mathrm{~cm}$ above the top of the support and the others were located $1 \mathrm{~cm}$ from each other. All the thermocouples used were mineral-insulated integrally metal-sheathed pre-welded type K (chromel-alumel) pairs of wire with an exposed junction. At the exposed junctions, the wires were $50 \mu \mathrm{m}$ in diameter. The uncertainty in temperature and mass was respectively $0.5^{\circ} \mathrm{C}$ and $2.5 \%$. Two visual cameras allowed observing the flame geometry. The ambient temperature was $21^{\circ} \mathrm{C}$ and the relative humidity was $50 \%$. At least five repetitions were made to collect reliable data. During the first $60 \mathrm{~s}$ of the sample burning, the flame fluctuates due to ethanol. Then, the flame becomes laminar as the fuel is only composed of the degradation gases. During this stage, the flame height decreases from 4 to $1.5 \mathrm{~cm}$. After $120 \mathrm{~s}$, the flame extinction begins. The combustion time lasts around $180 \mathrm{~s}$.

Table 1. Mass fractions of the main pyrolysis gases released by the degradation of the three vegetative fuels ( $\mathrm{x}=6$ or 8 and $\mathrm{y}=6,8$ or 10$)$

\begin{tabular}{|c|c|c|c|}
\hline Gas & Pinus laricio & Pinus halepensis & Erica arborea \\
\hline $\mathrm{CO}$ & 0.140 & 0.150 & 0.141 \\
\hline $\mathrm{CH}_{4}$ & 0.040 & 0.032 & 0.026 \\
\hline $\mathrm{H}_{2} \mathrm{O}$ & 0.074 & 0.070 & 0.047 \\
\hline $\mathrm{CO}_{2}$ & 0.616 & 0.663 & 0.718 \\
\hline $\mathrm{C}_{2} \mathrm{H}_{4}$ & 0.008 & 0.007 & 0.004 \\
\hline $\mathrm{C}_{2} \mathrm{H}_{6}$ & 0.015 & 0.011 & 0.005 \\
\hline $\mathrm{C}_{3} \mathrm{H}_{\mathrm{x}}$ & 0.016 & 0.012 & 0.007 \\
\hline $\mathrm{C}_{4} \mathrm{H}_{\mathrm{v}}$ & 0.090 & 0.055 & 0.052 \\
\hline $\mathrm{H}_{2}$ & 0.001 & 0.000 & 0.000 \\
\hline
\end{tabular}

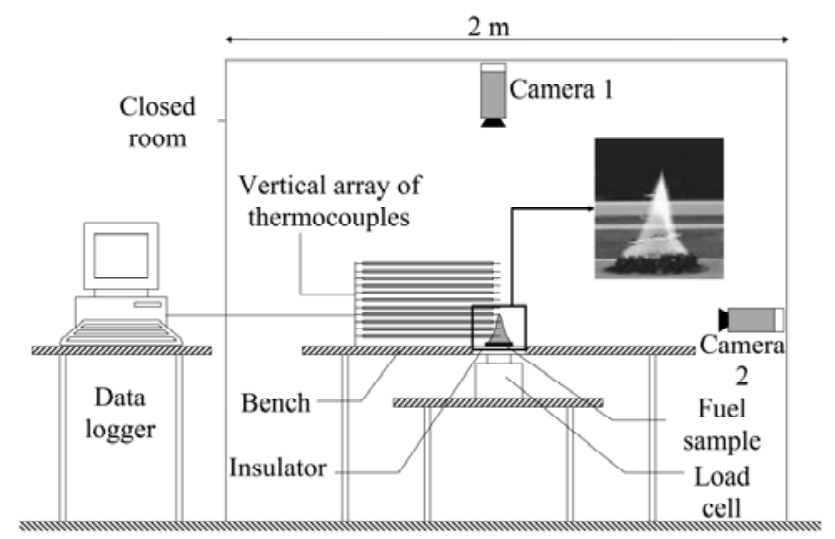

Fig. 1. Sketch of the experimental apparatus for the burning experiments

\section{NUMERICAL MODELLING}

This part describes the mathematical formulation and the chemical mechanisms used to model the burning experiments.

\section{Mathematical Formulation}

As this paper is focused on the study of the combustion in the gas phase, the crushed sample was represented as a burner. The model solved the two-dimensional, axisymmetric, time-dependant, laminar, reactive-flow Navier-Stokes equations coupled with radiation and transport: 


$$
\begin{aligned}
& \frac{\partial \rho}{\partial t}+\vec{\nabla} \rho \vec{V}=0 \\
& \frac{\partial \rho Y_{i}}{\partial t}+\rho \vec{V} \cdot \vec{\nabla} Y_{i}=\vec{\nabla}\left(\rho D_{i j} \vec{\nabla} Y_{i}\right)+\dot{\omega}_{i} \\
& \frac{\partial \rho \vec{V}}{\partial t}+\rho \vec{V} \vec{\nabla} \cdot \vec{V}=\vec{\nabla} p+\rho \vec{g}+\vec{\nabla} \cdot \overline{\bar{\tau}} \\
& \frac{\partial \rho e}{\partial t}+\rho \vec{V} \cdot \vec{\nabla} e=\vec{\nabla}(\lambda \vec{\nabla} T)+\vec{\nabla} \cdot \overrightarrow{R_{g}}+\vec{\nabla}\left(\rho \sum_{i=1}^{N} h_{i} D_{i j} \vec{\nabla} Y_{i}\right)-\vec{\nabla} \cdot(p \vec{V})+\vec{\nabla} \cdot(\overline{\bar{\tau}} \cdot \vec{V})+\dot{Q} \\
& \frac{d I(\vec{r}, \vec{s})}{d s}+a I(\vec{r}, \vec{s})=a \frac{\sigma T^{4}}{\pi}
\end{aligned}
$$

An analysis of parameterization and of sensitivity was used to determine the properties (viscosity, density, thermal conductivity and diffusivity) of the gas species and of the gas mixture as well as the numerical methods. The most efficient configuration in term of computational cost and accuracy was chosen. For each gas species, the kinetic theory [12] was used to compute the viscosity and the thermal conductivity whereas the specific heat capacity was a function of temperature. The density was calculated with the incompressible ideal-gas law. An ideal gas mixing law specified the viscosity and the thermal conductivity of the mixture. The kinetic theory was used to compute the diffusion coefficients. A mixing law defined the specific heat capacity. The Radiative Transfer Equation was solved by using the Discrete Ordinates Method (DOM) [13]. The studied domain was discretized in 144 directions. To obtain a simple model for radiation, the soot production/oxidation was not considered as the flames were not very sooty. The gas was approximated by a mixture of grey gases containing $\mathrm{CO}_{2}$ and $\mathrm{H}_{2} \mathrm{O}$. The absorption coefficient was calculated with the weighted-sum-of-grey-gases model (WSGGM) [14] and depends on the gas composition and the temperature. The governing equations for the gas phase were solved with a nonuniform grid using a finite-volumes procedure. Diffusion terms were approximated using a second-order central difference scheme. Convective terms were discretized with a first-order upwind scheme. The pressure-velocity coupling was handled by using the SIMPLE algorithm [15]. The resulting systems of linear algebraic equations were solved iteratively with the Algebraic Multigrid algorithm [16].

\section{Combustion mechanism}

To model the degradation gas oxidation, we used:

- The skeletal mechanism elaborated by Leroy et al. [10] for a mixture of carbon monoxide, carbon dioxide and methane. It was made to study the gas combustion in forest fires. It consists of 48 reactions and 20 species which include $\mathrm{C}_{2}$ hydrocarbons.

- The skeletal mechanism created by Peters et al. [17] for the combustion of methane. It is made up of 23 reactions and 14 gaseous species.

- The skeletal mechanism developed by Zhou and Mahalingam [18]. It was realized as part of forest fire modeling. It consists of 22 reactions and 14 species.

- A global mechanism (GM1) which considers only carbon monoxide as fuel. The CO oxidation produces $\mathrm{CO}_{2}$ and the reverse reaction is taken into account:

$$
\mathrm{CO}+0.5 \mathrm{O}_{2} \Leftrightarrow \mathrm{CO}_{2}
$$

The rates of production of the chemical species are obtained thanks to Arrhenius's laws (kmoles, $\mathrm{m}^{3}$, seconds and Kelvins) and are based on [19]. However, the activation energy for carbon monoxide was developed for turbulent combustion and is not adapted for laminar flows. Thus, it was decreased until the combustion sustains:

$$
\dot{\omega}_{\mathrm{CO}}=2.23910^{12}[\mathrm{CO}]\left[\mathrm{H}_{2} \mathrm{O}\right]^{0.5}\left[\mathrm{O}_{2}\right]^{0.25} \exp \left[-\frac{1.310^{8}}{R . T}\right]
$$




$$
\dot{\omega}_{\mathrm{CO}_{2}}=510^{8}\left[\mathrm{CO}_{2}\right] \exp \left[-\frac{1.310^{8}}{R . T}\right]
$$

- A global mechanism (GM2) which takes into account both carbon monoxide and methane as fuels. The chemical reactions for carbon monoxide are identical to the previous case (Eq. 6 to 8). The methane combustion is incomplete and produces carbon monoxide:

$$
\mathrm{CH}_{4}+1.5 \mathrm{O}_{2} \Rightarrow \mathrm{CO}+2 \mathrm{H}_{2} \mathrm{O}
$$

The rate of production is given by [19]:

$$
\dot{\omega}_{\mathrm{CH}_{4}}=5.01210^{11}\left[\mathrm{CH}_{4}\right]^{0.7}\left[\mathrm{O}_{2}\right]^{0.8} \exp \left[-\frac{210^{8}}{R . T}\right]
$$

The three skeletal mechanisms have been already tested in different configurations like perfectly stirred reactor, diffusion or premixed flames [10,17-18]. However, as for the two global models, it is the first time that these mechanisms are implemented in a CFD code and compared to experiments of forest fuel burnings. Their evaluation was carried out following two criteria: their computational time and their accuracy.

\section{Computational Domain}

As the experimental flames from the forest fuels were almost conical, an axisymmetric condition was applied. All the computations were carried out using a Cartesian non-uniform grid covering a space domain of $3.5 \mathrm{~cm}$ x $15 \mathrm{~cm}$ (Fig. 2.a). The white rectangle in Fig. 2.a. corresponds to the burner which represents the crushed sample. The grid contains 66600 cells with a mesh size of $0.2 \mathrm{~mm}$ respectively from $\mathrm{z}=0$ to $6 \mathrm{~cm}$ and from $\mathrm{r}=0$ to $6 \mathrm{~cm}$ along the vertical and radial direction. In the remaining part of the grid, a dilatation ratio of 1.03 was applied. Several tests were performed to ensure that the size of the domain did not influence the flame behavior and that numerical results were grid-independent.

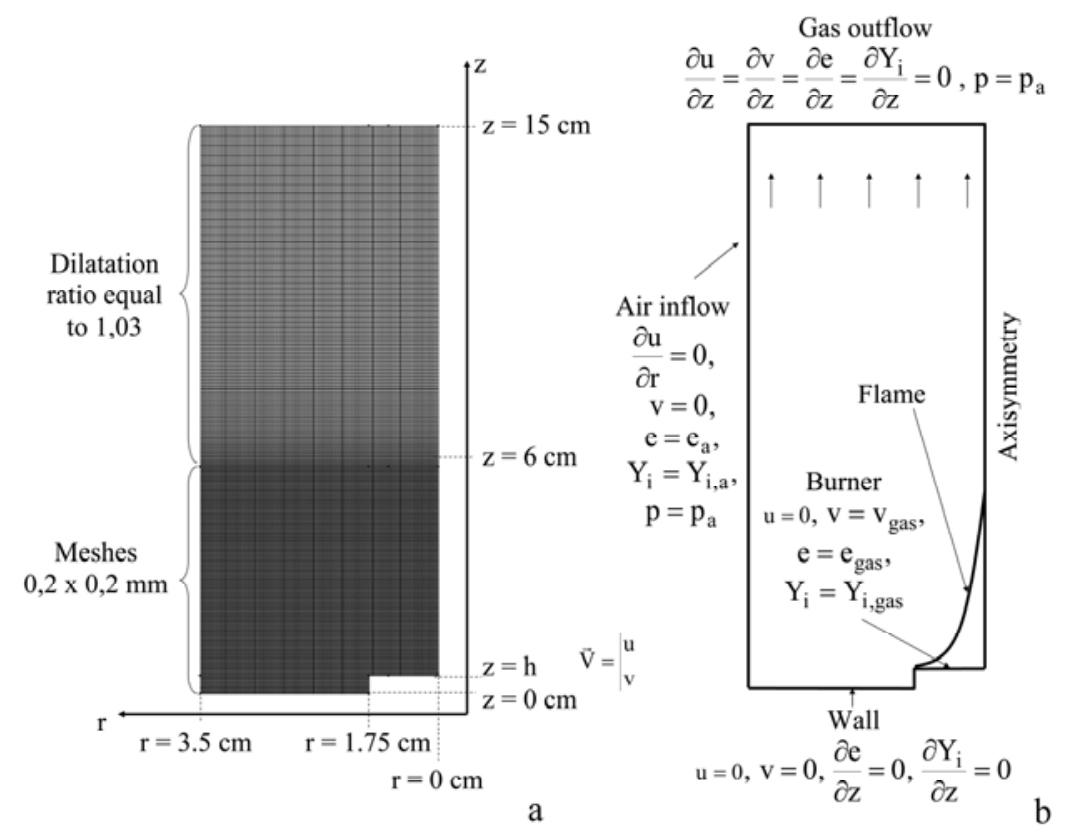

Fig. 2. Computational domain: a) grid b) boundary conditions

The boundary conditions are presented on Fig. 2.b. The initial conditions were directly deduced from the experimental data. The water fraction in most air was calculated from the relative humidity. The mass flow 
inlet of the burner was fitted from the experimental mass flow rate. The radius of the burner was equal to the experimental flame radius. The composition of the degradation gases released by the burner was based on the main gases analyzed with the tube furnace. A stationary solution of the flow field was first computed without reaction. Then, the ignition was carried out by applying a temperature of $1200 \mathrm{~K}$ near the burner. The modeling was performed on a $3.2 \mathrm{GHz}$ dual processor workstation shipped with 2GB RAM.

\section{STUDY OF COMBUSTION MECHANISMS}

The study of various combustion mechanisms was performed from the experiments of Pinus laricio at $60 \mathrm{~s}$ (i.e. at the beginning of the laminar stage of the flame). To determine the most suitable mechanisms, the work was focused on the temperature predictions in flame zone, where the combustion reactions take place.

\section{Composition of gas mixtures}

All the gases released by the forest fuels (Table 1) can not be included in the combustion mechanisms. $\mathrm{C}_{3}$ and $\mathrm{C}_{4}$ hydrocarbons have a greater sooting tendency than the other degradation gases. They participate also less to the gas combustion and were not considered in the following as soot production was taken into account. To determine which gas species are involved in the flame combustion, the skeletal mechanism of Leroy et al. [10] was used. This model allows indeed taking into account $C_{2}$ hydrocarbons. Two mixtures were tested. For mixture 1 , the mass fractions of $\mathrm{CO}, \mathrm{H}_{2} \mathrm{O}, \mathrm{CH}_{4}$ and $\mathrm{C}_{2}$ hydrocarbons correspond to the values of the gas analysis (Table 1). For composition 2, $\mathrm{C}_{2}$ hydrocarbons were not considered. For all mixtures, the mass fraction of $\mathrm{CO}_{2}$ is taken to set the sum of all mass fractions equal to 1 . Table 2 summarizes the initial conditions of the burner. Figure 3 presents a comparison between the numerical and the experimental temperatures along the flame axis. The range of the experimental temperatures is represented by vertical lines. The results computed with mixture 1 overestimate the temperatures. The maximum temperature is indeed about $150^{\circ} \mathrm{C}$ higher than the experimental data and its position is shifted of $0.75 \mathrm{~cm}$. The energy released by this composition is also too high to describe accurately the temperature in the fire flume and the combustion kinetics is not well represented in the flame. Conversely, the mixture 2 provides a temperature distribution close to the experiments in the flame. In the thermal plume, the predictions are slightly higher. In this part of the domain, the temperature distribution depends on the mixing between the burned gases and the ambient air. As the thermal plume becomes progressively turbulent, the laminar modeling used on the whole domain underestimates the cooling of the fire plume. Thus, it leads to a slight overestimation of the temperature in the thermal plume. According to these results, to match the experiments, the mass fractions of $\mathrm{CO}, \mathrm{CH}_{4}$ and $\mathrm{H}_{2} \mathrm{O}$ must be equal to the values obtained during the gas analysis. The other combustible species have to be neglected. This modeled gas composition depends on the hypotheses of simulation. The mechanisms of soot production/oxidation are not taken into account and the reactions are considered as complete. These assumptions increase the temperature prediction and lead to the decrease of the mass fraction of combustible gases in the modeled gas mixture.

Table 2. Initial conditions of the burner for the determination of the gas composition

\begin{tabular}{|c|c|c|}
\hline & Mixture 1 & Mixture 2 \\
\hline $\mathrm{CO}$ & 0.140 & 0.140 \\
\hline $\mathrm{CH}_{4}$ & 0.040 & 0.040 \\
\hline $\mathrm{H}_{2} \mathrm{O}$ & 0.074 & 0.074 \\
\hline $\mathrm{CO}_{2}$ & 0.722 & 0.746 \\
\hline $\mathrm{C}_{2} \mathrm{H}_{4}$ & 0.008 & - \\
\hline $\mathrm{C}_{2} \mathrm{H}_{6}$ & 0.015 & - \\
\hline LHV (MJ/kg) & 4.51 & 3.42 \\
\hline Mass flow rate (kg.s ${ }^{-1}$ ) & \multicolumn{2}{|c|}{$4.4710^{-6}$} \\
\hline Radius (cm) & \multicolumn{2}{|c|}{1.47} \\
\hline $\mathrm{T}\left({ }^{\circ} \mathrm{C}\right)$ & \multicolumn{2}{|c|}{413.5} \\
\hline
\end{tabular}




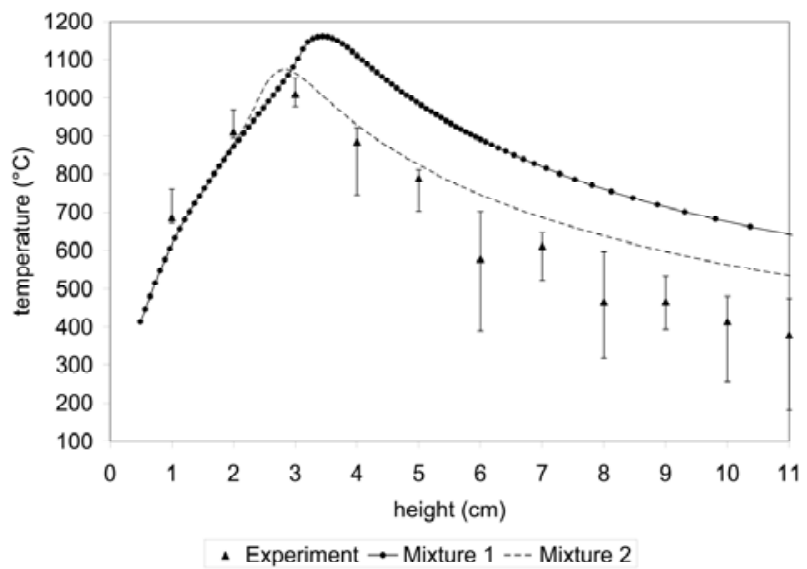

Fig. 3. Comparison between experimental and numerical temperatures obtained with the two gas mixtures along the flame axis with the skeletal mechanism of Leroy et al [10].

\section{Study of skeletal mechanisms}

The number of reactions and species in the skeletal mechanism proposed by Leroy et al. [10] is significant. It leads to a long computational time (about 1 week on our workstation) which corresponds to five times the duration necessary to compute the flow field without reaction. To decrease the computational time, the other skeletal mechanisms which consist of fewer reactions were studied. Their computational time was reduced by half compared to the mechanism of Leroy et al. [10]. Figure 4 presents a comparison of the three skeletal mechanisms along the flame axis. The three temperature curves are equivalent. The mechanism elaborated by Zhou and Mahaligam [18] generates however higher temperatures than the two others. And its curve presents an inflection point just before the maximum temperature. In the flame zone, the predicted temperatures obtained with the mechanisms of Leroy et al. [10] and of Peters et al. [17] are close and remain in the range of the experimental data. The mechanism of Peters et al. [17] allows also modeling the flame of forest fuels without losing accuracy and with a reduced computational time. However, in spite of this decrease, the computing time remains too long as it is twice duration required to compute the flow field without reaction. It appears also that the skeletal mechanisms are not adapted to model the gas oxidation in wildland fire simulations.

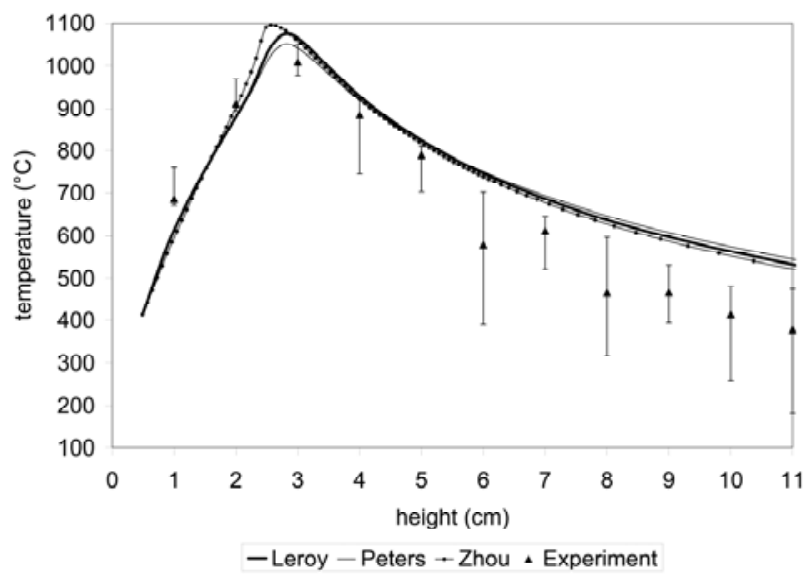

Fig. 4. Comparison of the numerical temperatures obtained with the three skeletal mechanisms

\section{Study of global mechanisms}

As the skeletal mechanisms were not suitable for a wildfire simulator, global combustion mechanisms were examined. For testing mechanism GM2, mixture 2 (Table 2) was used. As mechanism GM1 does not take into account methane, two different compositions (called mixture 3 and 4, hereafter) based on mixture 2 
were considered. Mixture 3 was established according to Grishin's hypothesis [5]. In this approach currently used in forest fire modeling, the mass fraction of $\mathrm{CO}$ is equal to the sum of the initial mass fractions of $\mathrm{CO}$ and $\mathrm{CH}_{4}$. In mixture 4, the mass fraction of $\mathrm{CO}$ corresponds to the same low heating value as mixture 2. As previously, for mixtures 3 and 4 , the mass fraction of $\mathrm{CO}_{2}$ is taken to set the sum of all mass fractions equal to 1 . A summary of the inputs used for this study is provided in Table 3 . To insure that the predictions obtained with these mechanisms were correct, the temperatures were compared to the results of the mechanism of Peters et al. [17] and to the experiments. Figure 5 shows the experimental temperatures and the predictions along the flame axis obtained with the three mechanisms. Mechanism GM1 with mixture 3 underestimates significantly the temperatures (about $200^{\circ} \mathrm{C}$ ) and modifies the maximum position, which is $1.4 \mathrm{~cm}$ lower. The energy released is also too low to describe accurately the temperature in the fire flume and the combustion kinetics is not well represented in the flame. The association of mixture 4 with mechanism GM1 provides better results. The maximum temperature is indeed very close to that obtained with Peters' mechanism. However, its position appears closer to the burner (about $0.7 \mathrm{~cm}$ what represents an error of $25 \%$ ). Thus, this configuration does not allow predicting accurately the combustion kinetics in the flame. Conversely, mechanism GM2 reproduces correctly the temperatures obtained with the skeletal mechanism. The maximum temperature is however slightly lower but it remains close to the experimental measurements. Thus, thanks to the incorporation of methane, mechanism GM2 and the skeletal mechanism of Peters et al. [17] provide equivalent results. Moreover, the use of this global mechanism which considers only two reactions steps, decreases considerably the computational time. It is indeed equal to the duration necessary to compute the flow field without reaction. The global mechanism GM2 seems also to answer the two criteria (accuracy and low computational time) established for the incorporation of combustion model in forest fire approaches.

Table 3. Burner inputs for the determination of the global mechanism

\begin{tabular}{|c|c|c|c|}
\hline Composition & Mixture 2 & Mixture 3 & Mixture 4 \\
\hline Mechanism & GM2 and Peters et al. & \multicolumn{2}{|c|}{ GM1 } \\
\hline $\mathrm{CO}$ & 0.140 & 0.180 & 0.338 \\
\hline $\mathrm{CH}_{4}$ & 0.040 & - & - \\
\hline $\mathrm{H}_{2} \mathrm{O}$ & 0.074 & 0.074 & 0.074 \\
\hline $\mathrm{CO}_{2}$ & 0.746 & 0.746 & 0.588 \\
\hline LHV $(\mathrm{MJ} / \mathrm{kg})$ & 3.42 & 1.82 & 3.42 \\
\hline Mass flow rate $\left(\mathrm{kg} . \mathrm{s}^{-1}\right)$ & \multicolumn{3}{|c|}{1.47} \\
\hline Radius $(\mathrm{cm})$ & 413.5 \\
\hline $\mathrm{T}\left({ }^{\circ} \mathrm{C}\right)$ & \multicolumn{3}{|c|}{413} \\
\hline
\end{tabular}

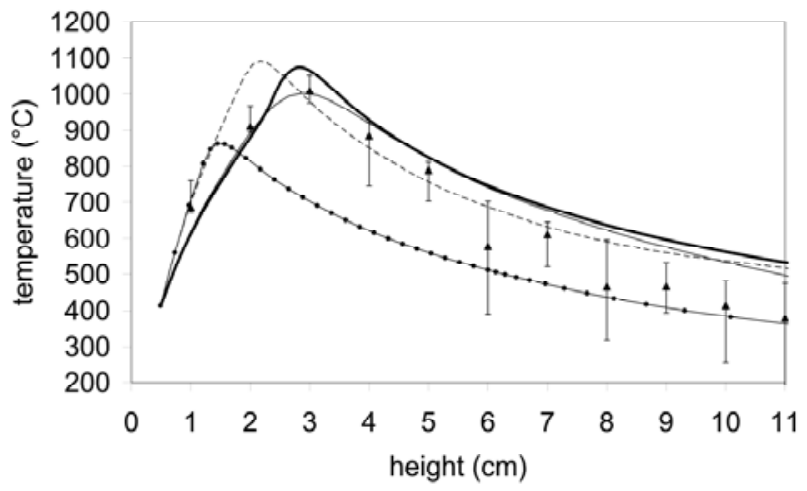

\footnotetext{
1 Experiment - Peters - Mixture 2 - GM2 - Mixture 2

-GM1 - Mixture 3 --..GM1 - Mixture 4
}

Fig. 5. Experimental and computed temperatures obtained with the different mechanisms along the flame axis 


\section{COMPARISON WITH EXPERIMENTS}

\section{Validation with other vegetative fuels}

In the earlier section, a global mechanism was proposed and tested from the experimental data of Pinus laricio. The first step of the validation of GM2 was carried out with the two other vegetative fuels: Pinus halepensis and Erica arborea for the same time used for Pinus laricio (i.e. 60 s). The inputs for the burner are presented in Table 4. Figures 6.a-b show the experimental and simulated temperatures along the flame axis for Pinus halepensis and Erica arborea. As for Pinus laricio, the predicted temperatures for the two other crushed samples are in a general good agreement with the experimental data. In the fire plume, the predicted temperatures are indeed close to the experimental measurements. The mechanism GM2 is thus able to predict the temperature distribution for different fuels.

Table 4. Burner inputs for Pinus halepensis and Erica arborea at $60 \mathrm{~s}$

\begin{tabular}{|c|c|c|}
\hline & Pinus halepensis & Erica arborea \\
\hline $\mathrm{CO}$ & 0.150 & 0.141 \\
\hline $\mathrm{CH}_{4}$ & 0.032 & 0.026 \\
\hline $\mathrm{H}_{2} \mathrm{O}$ & 0.070 & 0.047 \\
\hline $\mathrm{CO}_{2}$ & 0.748 & 0.787 \\
\hline $\left.\mathrm{T} \mathrm{(}{ }^{\circ} \mathrm{C}\right)$ & 324.9 & 481.7 \\
\hline Mass flow rate (kg.s $\left.{ }^{-1}\right)$ & $4.9010^{-6}$ & $4.7710^{-6}$ \\
\hline Radius $(\mathrm{cm})$ & 1.63 & 1.72 \\
\hline
\end{tabular}
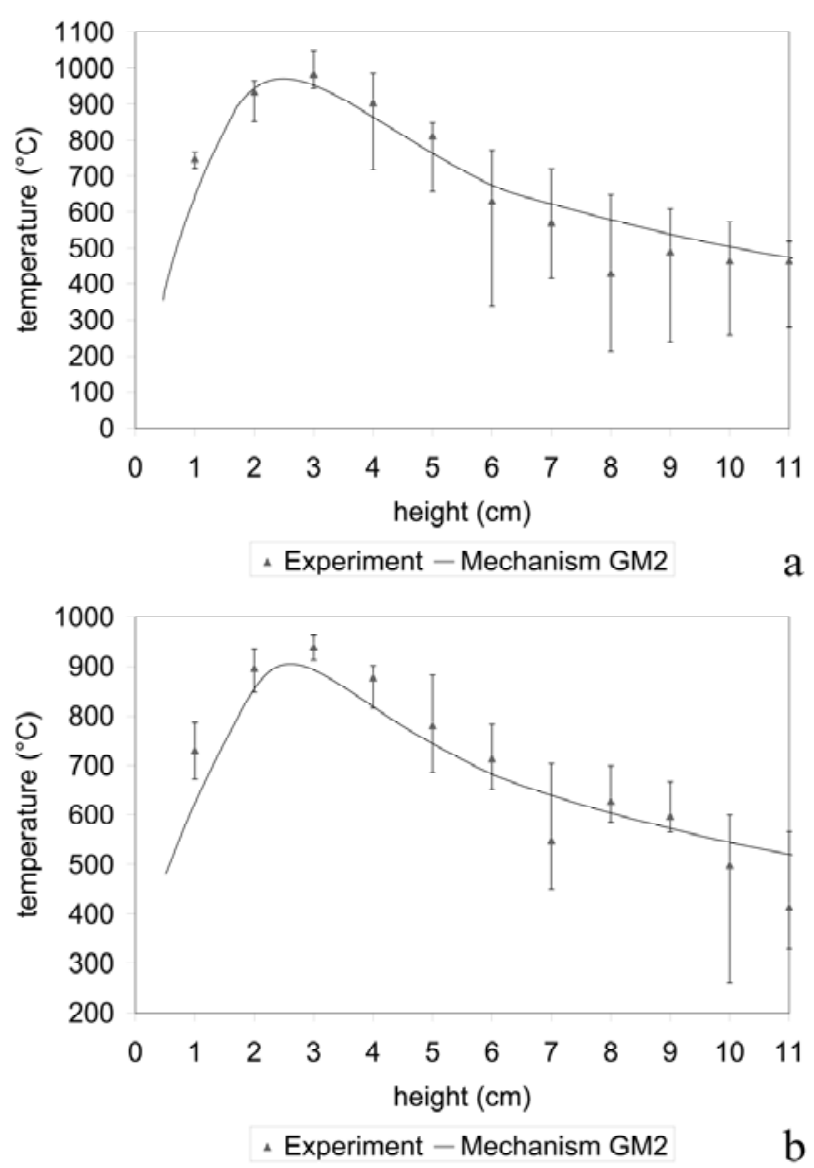

Fig. 6. Experimental and computed temperatures obtained with mechanism GM2 at 60 s for a) Pinus halepensis b) Erica arborea 


\section{Validation at different times}

The second test of the mechanism GM2 was performed at different times with the three crushed samples. The gas composition released by the burner and the temperature correspond to the values of Table 3 and 4 . The temperature predictions were compared to the experimental data at $80 \mathrm{~s}$. This time is representative to the laminar activity of the flames too. However, the visual flame height is smaller than that at $60 \mathrm{~s}$ because of a lower mass flow rate and flame radius (Table 5). Figures 7.a-c present the experimental and computed temperatures along the flame axis for the three fuels at $80 \mathrm{~s}$. For the three species, the predicted temperatures agree with the experimental data. In the flame zone, the predicted temperatures are indeed very close to the mean experimental measurements and remains in the range of the experiments. Thus, mechanism GM2 provides a good representation of the temperature distribution whatever the time considered and also whatever the mass burning rate of the crushed fuels.

Table 5. Mass flow rates of the degradation gases and burner radiuses at $80 \mathrm{~s}$ for the three fuels

\begin{tabular}{|c|c|c|c|}
\hline & Pinus laricio & Pinus halepensis & Erica arborea \\
\hline Mass flow rate (kg.s ${ }^{-1}$ ) & $3.0010^{-6}$ & $3.2710^{-6}$ & $3.1510^{-6}$ \\
\hline Radius $(\mathrm{cm})$ & 1.25 & 1.48 & 1.61 \\
\hline
\end{tabular}
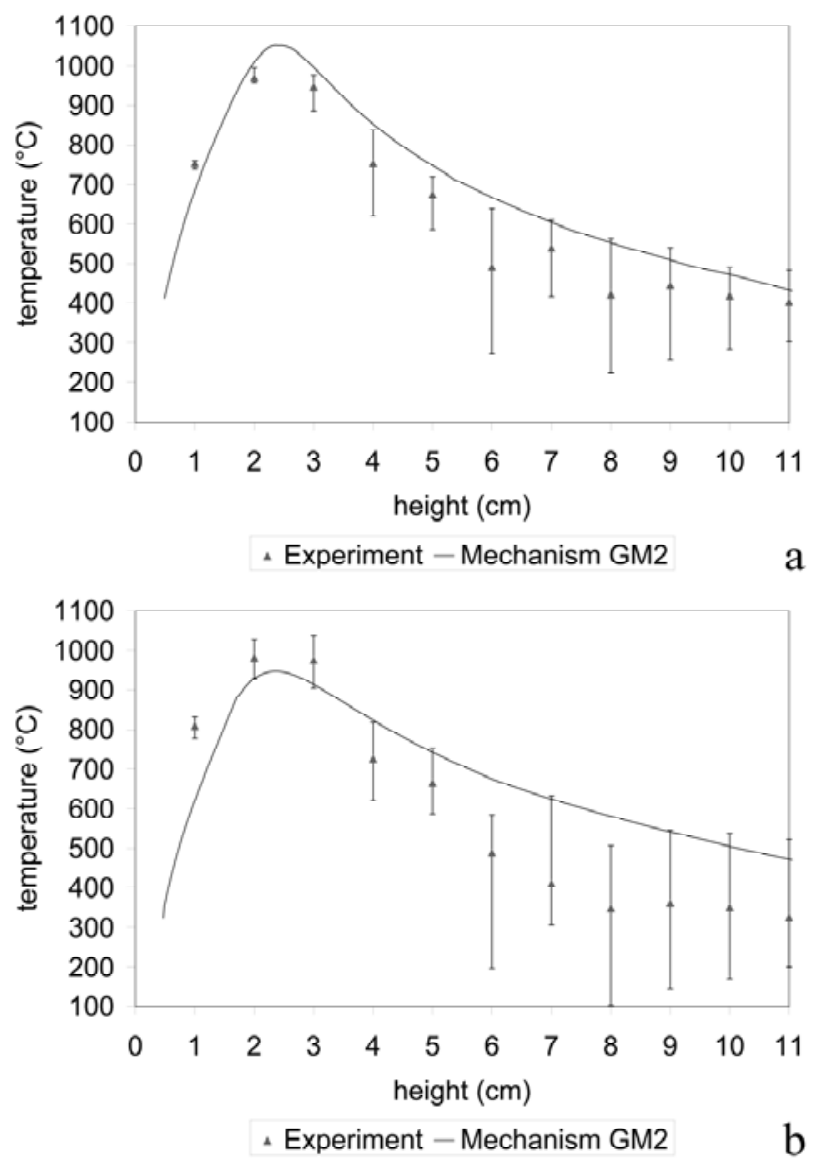


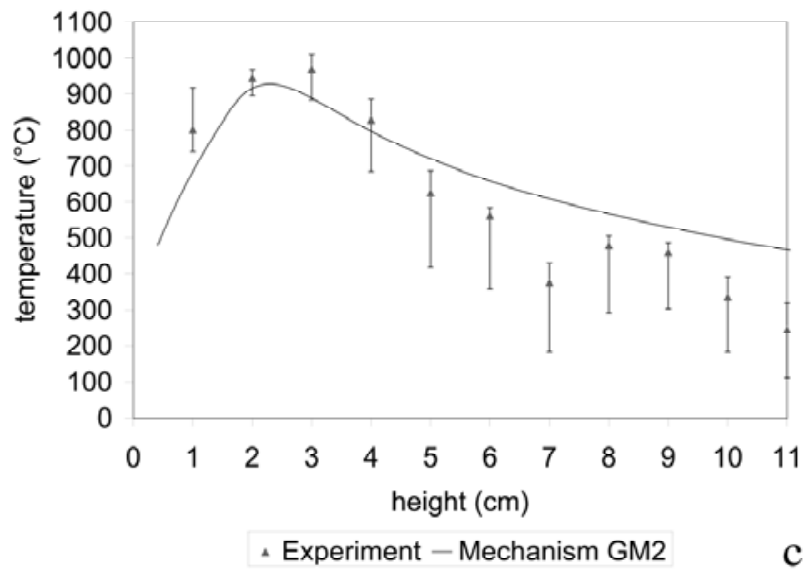

Fig. 7. Experimental and computed temperatures obtained with mechanism GM2 along the flame axis at $80 \mathrm{~s}$ for a) Pinus laricio b) Pinus halepensis c) Erica arborea

\section{CONCLUSION}

In this paper, a combustion model able to predict the laminar flames of three crushed forest fuels was defined. Thanks to the skeletal mechanism of Leroy et al., different gas mixtures based on the experimental data were investigated in order to determine a modeled gas composition allowing predicting the flames. To match the experiments, the mass fractions of $\mathrm{CO}, \mathrm{CH}_{4}$ and $\mathrm{H}_{2} \mathrm{O}$ must be equal to the values obtained during the gas analysis. The other combustible species have to be neglected. Next, various skeletal mechanism were tested to determine a mechanism producing the same results as those of Leroy et al. [10] but needing a lower computational time. We demonstrated that the combustion mechanism elaborated by Peters et al. [17] provides close temperature distribution with a computation time decreased by half. Nevertheless, it remains too high in order to be included in forest fire approaches. Then, two global mechanisms were investigated. Comparison of the experimental results with these models reveals that the mechanism considering only carbon monoxide does not allow predicting correctly the temperature distribution for laminar flow. On the contrary, the global mechanism including both methane and carbon monoxide produces numerical temperatures close to the skeletal mechanism with a lower computational time. Finally, this combustion mechanism was tested with three vegetative fuels at different times of their burning. It provides encouraging results under laminar conditions. However, this combustion model needs to be tested under turbulent conditions more representative of forest fires. To proceed, static and spreading turbulent fires will be investigated.

\section{ACKNOWLEDGEMENT}

We thank J.P. Garo and J.P. Vantelon from LCD - UPR 9028 CNRS, ENSMA, University of Poitiers for their help in this work.

\section{REFERENCES}

[1] McArthur, A.G., "Weather and grassland fire behaviour", Leafter $n^{\circ} 100$, Australian Forest and Timber Bureau, 1966, 23 p.

[2] Rothermel, R.C., "A mathematical model for predicting fire spread in wildland fuels”, INT-115, USDA Forest Service, 1972, 40 p.

[3] Albini, F.A., (1986) Wildland Fire Spread by Radiation - A Model Including Fuel Cooling by Natural Convection, Combustion Science and Technology 45:101-113, doi:10.1080/00102208608923844.

[4] Morandini, F., Simeoni, A., Santoni, P.A., and Balbi, J.H., (2005) A model for the spread of fire across a fuel-bed incorporating the effects of wind and slope, Combustion Science and Technology, 177:1381-1418, doi:10.1080/00102200590950520. 
[5] Grishin, A.M., Mathematical Modeling of forest fires and new methods of fighting them, Publishing House of the Tomsk State University, Tomsk, 1997, 390 p.

[6] Linn, R.R., “A transport model for prediction of wildfire behaviour", University of California (UC-905), Los Alamos National Laboratory Report No. LA-13334-T, 1997.

[7] Simeoni, A., Santoni, P., Larini, M., and Balbi, J.H. (2001) On the wind advection influence on the fire spread across a fuel bed: modelling by a semi-physical approach and testing with experiments, Fire Safety Journal 36:491-513, doi:10.1016/S0379-7112(00)00063-1.

[8] Morvan, D. and Dupuy, J.L. (2001) Modeling of fire spread through a forest fuel bed using a multiphase formulation, Combustion and Flame 127:1981-1994, doi:10.1016/S00102180(01)00302-9.

[9] Tihay, V., Simeoni, A., Santoni, P.A., Garo, J.P., and Vantelon, J.P., "Influence of degradation gases on laminar flames from forest fuels”, Mediterranean Combustion Symposium 07 Monastir, 2007.

[10] Leroy, V., Leoni, E., Santoni, P.A., Bertin, V., Falaise D., and Bonneau, L., "Combustion of pyrolysis gas involved in Wildland fire: experimental study", Mediterranean Combustion Symposium 07 Monastir, 2007.

[11] Safi, M.J., Mishra, I.M., and Prasad, B., (2004) Global degradation kinetics of pine needles in air, Thermochimica Acta, 412:155-162, doi:10.1016/j.tca.2003.09.017.

[12] McGhee, H.A., Molecular Engineering, McGraw-Hill, New York, 1991, p. 480.

[13] Chui, E.H., and Raithby, G.D., (1993) Computation of radiant heat transfer on a nonorthogonal mesh using the finite-volume method, Numerical Heat Transfer 23:269-288, doi:10.1080/10407799308914901.

[14] Fluent, FLUENT 6.2 User’s Guide, Fluent Inc., Lebanon, 2005.

[15] Patankar, S.V., Numerical Heat Transfer and Fluid Flow, Hemisphere Publishing Corporation, Washington, D.C, 1980, p. 197.

[16] Hutchinson, B. R., and Raithby, G.D., (1986) A multigrid method based on the additive correction strategy, Numerical Heat Transfer 9:511-537, doi:10.1080/10407788608913491.

[17] Peters, N., and Kee, R.J. (1987) The computation of stretched laminar methane air diffusion flames using a reduced four step mechanism, Combustion and Flame 68:17-29, doi:10.1016/00102180(87)90062-9.

[18] Zhou, X., and Mahalingam, S. (2001) Evaluation of reduced mechanism for modelling combustion of pyrolysis gas in wildland fire, Combustion Science and Technology 171: 39-70, doi:10.1080/00102200108907858.

[19] Dryer, F., and Glassman, I., "High temperature oxidation of $\mathrm{CO}$ and $\mathrm{CH}_{4}$, Proceeding of the Combustion Institute, 1973, 14: 987-1003. 